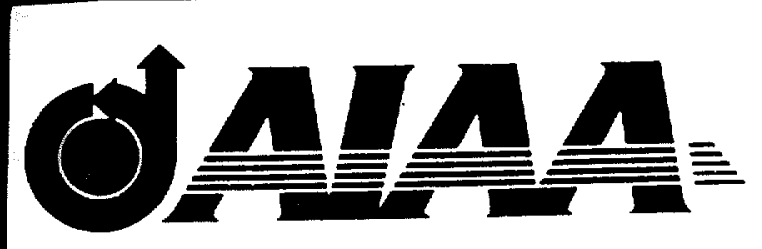

\title{
AIAA 96-0777 \\ Generation of Comprehensive Longitudinal Aerodynamic data using Dynamic wind tunnel simulation
}

\author{
M.S.Rajamurthy \\ National Aerospace Laboratories \\ Bangalore, INDIA
}

\section{4th Aerospace Sciences Meeting \& Exhibit January 15-18, 1996/ Reno, NV}




\title{
GENERATION OF COMPREHENSIVE LONGITUDINAL AERODYNAMIC DATA USING DYNAMIC WIND TUNNEL SIMULATION
}

\author{
M S.Rajamurthy* \\ National Aerospace laboratories, \\ P.O.Box 1779, Bangalore 560017 \\ INDIA
}

\begin{abstract}
$\underline{\text { Abstract }}$
This paper presents a novel method of generating comprehensive Longitudinal aerodynamic data of aircraft using dynamic wind tunnel simulation. The method combines measurement of motion and force responses of aircraft model to control inputs in dynamic wind tunnel simulation. The data generated includes trim Lift characteristics, Longitudinal stability derivatives and neutral point. In addition, large amplitude Iiff and pitching moment responses characterising the unsteady aerodynamic behaviour can also be generated.

The method is demonstrated using a generic delta wing aircraft model with one degree of freedom in pitch flown in a low speed dynamic wind tunnel. The model pitch attitude and Lift responses to elevon inputs are measured and used to deduce longitudinal aerodynamic data. Comparison of these results with static test data and Datcom estimates show good agreement.
\end{abstract}

\section{Nomenclature}

$\bar{c}$ mean aerodynamic chord, $\mathbf{m}$

$h_{c}$ Location of c,g, fraction of $\bar{c}$

$h_{n}$ Location of neutral point, fraction of $\bar{c}$

$I_{y}$ Moment of inertia about pitch axis, $\mathrm{Kg} \cdot \mathrm{m}^{2}$

$L \quad$ Lift force, $\mathrm{N}$

M Pitching moment, N-m

$q$ Body axis pitch rate, deg/sec or rad/sec

$\bar{q}$ Free stream dynamic pressure, $\mathrm{N} / \mathrm{m}^{2}$

$\mathrm{S}$ Wing reference aren, $\mathrm{m}^{2}$

SM Static margin, $\left(h_{n}-h_{c}\right)$

$V$ Free stream yelocity, $\mathrm{m} / \mathrm{sec}$

$\alpha \quad$ Angle of attack, deg or rad

\footnotetext{
$\overline{{ }^{*} \text { Scientist, Flight Mechanics \& Control Division }}$

Copyright $(\odot) 19 \%$ by M.S. Rajamurthy. Published by American Institute of Aeronautics and Astronautics, Inc. with permission
}

$\delta \quad$ Control surfacedeflection, deg or rad

$\theta \quad$ Pitch attitude, deg or rad

$C_{L} \quad$ Lift coefficient, $C_{L}=L / \bar{q} S$

$C_{L_{\mathbf{a}}} \quad$ Lift curve slope, per rad

$C_{m} \quad$ Pitching moment coefficient, $C_{m}=M / \bar{q} S c$

$C_{\boldsymbol{m}_{\boldsymbol{\alpha}}} \quad$ Static stability derivative, per rad

$\left(C_{m_{q}}+C_{m_{\dot{\alpha}}}\right)$ Pitch Damping derivative, per rad

$C_{m_{e}}$

Pitch Control derivative, per rad

\section{$\underline{\text { Abbreviations }}$}

$\mathrm{ADC}$ Analog to Digital Conversion

c.g. Center of gravity

DOF Degrees of freedom

R/C Radio controlled

\section{Introduction}

Study of stability and control characteristics of aircraft is part of its design process and includes static trim, static stability, dynamic stability and responses. This requires static aerodynamic forces and moments as well as dynamic stability derivative data. While static aerodynamic data is used to determine trim and static stability, dynamic stability derivatives are used to study dynamic stability and response characteristics.

During preliminary design, both static aerodynamic and dynamic stability derivative data are estimated using analytical expressions and empirical methods based on experimental database'. Once the configuration is frozen, aerodynamic force and moment data is generated from static wind tunnel tests. Dynamic Stability derivatives are obtained from force and moment data on models subjected to free or forced oscillations in $a$ wind tunnel using derivativerigs ${ }^{2}$. 
Dynamic wind tunnel simulation is an alternative technique for determining stability derivatives $^{\mathbf{3 - 8}}$. This technique relies on conducting flight test like experiments in a wind tunnel using dynamically scaled models. The models have rotary and/or translational DOF and are equipped with servo controlled surfaces to excite the model just as in real flight. Miniature incidence, angular rate and acceleration sensors pick up the dynamic response of the model. he model motion responses to specific control inputs are generated and from these measured responses stability derivatives are estimated using parameter estimation techniques.

The measurement of aerodynamic forces on a model in the dynamic wind tunnel simulation for estimating stability derivatives has not been reported in the literature. The combined measurement of aerodynamic force and motion responses significantly enhances the capability of dynamic wind tunnel simulation and comprehensive aerodynamic data can be generated. This paper presents such a dynamic wind tunnel simulation and demonstrates it using a generic delta wing aircraft model with pitch DOF.

\section{Novel dvnamic wind tunnel simulation}

At the Flight Mechanics \& Control division of National Aerospace Laboratories, India, dynamic wind tunnel simulation with only rotary DOF has been used to estimate important dynamic stability and damping derivatives 7,8 . The advantage of having only rotary DOF is the simplicity of the model mount in the form of gimbals and the absence of any cable or heave travel mechanisms. However, with rotary DOF, only moment derivatives can be estimated.

The scope of dynamic wind tunnel simulation with rotary DOF can be enhanced by measuring aerodynamic forces in addition to motion variables. In case of a model with one DOF in pitch, measurement of Lift enables the estimation of Lift derivatives. In dynamic wind tunnel simulation the model is always trimmed at a reference angle of attack. Thus Trimmed Lift data can be obtained directly. Since Lift curve slope $C_{L_{n}}$ can be estimated at each of the trimmed angle of attack along with static stability $C_{m_{1}}$, neutral point canbe deduced from a single test.

As the Lif is measured directly large amplitude responses at high angles of attack can be easily generated. While Lift time histories are measured directly pitching moment can be computed from pitch attitude responses. Conventionally, these responses are generated in large amplitude rigs ${ }^{9.11}$ where the complete model is forced by a drive mechanism to undergo large amplitude excursions in the wind tunnel and the aerodynamic forces and moments acting on the model are measured.

The large amplitude responses generated using dynamic wind tunnel simulation are more realistic for the following reasons:

i. The model is initially trimmed at a reference angle of attack.

ii. For a tailless configuration like a delta wing pitch control surface forms an appreciable part of the wing and its deflection influences the wing load distribution.

iii. The response is generated by moving the control surface.

iv. As the model is excited aerodynamically using the control surface, aerodynamic lag associated with it is taken care of in the dynamic simulation.

Thus, in a single experimental set-up, comprehensive Longitudinal aerodynamic data in the form of trimmed Lift characteristics, dynamic stability derivatives, neutral point, and large amplitude Lift and pitching moment responses can be generated.

\section{Model \& Instrumentation}

The model chosen for demonstrating the method is a generic delta wing aircraft configuration adopted from a delta wing-body configuration for which extensive static test data is available $^{12}$. The wing is a delta planform of aspect ratio $2.3 \mathrm{i}$ and a leading edge sweep of $60 \mathrm{deg}$. Both leading \& trailing edges are bevelled. Fuselage is a cylindrical body with Ogive nose. The model has elevons for pitch control. Figure 1 shows the geometrical details of the model. The elevons have a travel off $30 \mathrm{deg}$. and are driven by a high torque miniature WC servo. The model is fabricated using plywood and Balsa sheet to make it light weight and it's pitch inertia representative of the dynamic scaling of a combat aircraft. The reference dimensions and pitch inertia of the model are given in table.1

A single axis gimbal fixed to the model

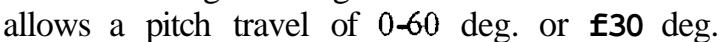


Precision ball bearings are used to minimise gimbal friction. The model is balanced to locate it's $\mathrm{c} . \mathrm{g}$. at the center of the gimbal axes which is chosen at $0.25 \bar{c}$. The model with gimbal is fixed to the vertical strut located at the center of the tunnel test section. Figure 2 shows the model in the wind turnel.

A precision continuous type conductive plastic potentiometer mounted to the gimbal measures pitch attitude. Lift is measured using a load cell fixed to the vertical support strut (fig. 2. The load cell measures the total force acting along the strut and is designed to minimise the effect of side loads on the measurement. It's output is amplificed using a bridge amplifier. During wind OFF and wind $\mathrm{ON}$ it measures the model weight and the difference between Lif and model weight respectively. The elevon deflection is measured by the feedback potentiometer in the WC servo. The model inputoutputs are acquired on a Personal computer using a 12 bit ADC card at a sampling rate of 80 per second. The Elevon commands are generated on the Personal computer and fed to $\mathrm{R} / \mathrm{C}$ servo. The sensors are precisely calibrated prior to wind tunnel tests. Pitch rate and pitch acceleration are derived from pitch attitude using numerical differentiation and filtering. The adequacy of pitch attitude measurement was ascertained by measuring pitch rate and pitch acceleration using rate gyro and accelerometer respectively and comparing the same with that derived by numerical differentiation.

\section{Dynamic Wind tunnel simulation Tests}

Tests are conducted in the Low speed dynamic wind tunnel of Flight Mechanics \& Control Division, National aerospace Laboratories. This is an open circuit induced draught type tunnel with $1.2 \mathrm{~m} \times 1.2 \mathrm{~m}$ test section and a variable speed capability of $\mathbf{2 0 - 4 5} \mathrm{m} / \mathrm{sec}$. The present tests are conducted at a dynamic pressure of $245 \mathrm{~N} / \mathrm{m}^{2}$ corresponding to a tunnel speed of $21.5 \mathrm{~m} / \mathrm{sec}$. The test Reynolds number is $0.42 \times 10^{6}$ based on $F$. The model is trimmed at several angles-of-attack up to $\mathbf{4 0} \mathrm{deg}$. In the range $\boldsymbol{0}$ to $\mathbf{2 0} \mathrm{deg}$., at each trim angle-of-attack model response to an elevon doublet input is acquired. Typical data length is of $\mathbf{1 2 . 5}$ second duration corresponding to $\mathbf{1 0 0 0}$ samples. To generate large amplitude responses, the model is trimmed at a reference angle of attack and excited by a step elevon input. This is repeated by varying the amplitude of the elevon step.

Lift is deduced from the load cell output by subtracting wind off tare and $C_{L}$ is computed by normalising it. The pitching moment coefficient is computed using the relation

$$
c_{m}=\frac{I_{y}}{\bar{q} \cdot S \cdot \bar{c}} \cdot \ddot{\theta}
$$

\section{Analusis and discussion of results}

The wind tunnel model with pitch DOF is modelled as a linear time-invariant system whose input is $\delta_{e}, \theta$ and $\mathrm{q}$ are the states, and $\dot{q}, \boldsymbol{q}, \boldsymbol{\theta}$ and $C_{L}$ are the measurements. In these experiments $\theta$ is same as $\boldsymbol{a}$.

The state space equations are given by

$$
\left[\begin{array}{c}
\dot{q} \\
\dot{\theta}
\end{array}\right]=\left[\begin{array}{cc}
\left(M_{q}+M_{\dot{\alpha}}\right) & M_{\alpha} \\
1 & 0
\end{array}\right] \cdot\left[\begin{array}{l}
q \\
\theta
\end{array}\right]+\left[\begin{array}{c}
M_{\delta_{e}} \\
0
\end{array}\right] . \delta_{e}
$$$$
\left[\begin{array}{c}
\dot{q} \\
q \\
\theta \\
C_{L}
\end{array}\right]=\left[\begin{array}{cc}
\left(M_{q}+M_{\dot{\alpha}}\right) & M_{\alpha} \\
1 & 0 \\
0 & 1 \\
C_{L_{q}} \cdot \bar{c} / 2 V & C_{L_{\alpha}}
\end{array}\right] \cdot\left[\begin{array}{l}
q \\
\theta
\end{array}\right]+\left[\begin{array}{c}
M_{\delta_{\varepsilon}} \\
0 \\
0 \\
C_{L_{\delta_{e}}}
\end{array}\right] \cdot \delta_{e}
$$

$$
\begin{aligned}
& \text { here } M_{\alpha}=\frac{C_{m_{a}} \cdot \bar{q} \cdot S \cdot \bar{c}}{I_{y}} \\
& \left(M_{q}+M_{\dot{\alpha}}\right)=\frac{\left(C_{m_{q}}+C_{m_{\dot{a}}}\right) \cdot \bar{q} \cdot S \cdot \bar{c}}{I, .2 V} \\
& M_{\delta_{e}}=\frac{C_{m_{\delta_{e}}} \cdot \bar{q} \cdot S \cdot \bar{c}}{I_{y}}
\end{aligned}
$$

Figure 3 shows the plot of trimmed Lift coefficient obtained from experiments as a function of angle of attack Superimposed on this is the Lift coefficient data for the wing-body ${ }^{12}$. Due to Elevon deflection for trim, trimmed Lift is less than the Wing-body Iift. The angle of attack for maximum Iiff is a round the same as that for the wing-body. Figure 4 shows a typical response of the model to an elevon doublet input. Pitch rate and pitch acceleration shown are derived from pitch attitude measurement by numerical differentiation and filtering.

The parameters of the state space model are estimated using Maximum-Likelihood Estimation (MLE) procedure ${ }^{13}$. The nondimensional derivatives are obtained from the model parameters using equation 4. The estimated derivatives are given in table 2. The Static derivatives $C_{L_{a}}$ and $C_{m_{a}}$ are compared with static data ${ }^{12}$. As Pitch

American Institute of Aeronautics and Astronautics 
damping $\left(C_{m_{q}}+C_{m_{i}}\right)$ and Pitch control effectiveness $C_{\boldsymbol{m}_{\boldsymbol{z}}}$ data was not available for comparison the same were estimated using Datcom!. Figure5 shows these

comparisons. Dynamic wind tunnel simulation ıssults are in close agreement with static data and Datcom estimates except for Pitch control effectiveness. The discrepancy in $C_{\boldsymbol{m}_{\boldsymbol{q}}}$ is due to the inaccuracy in the elevon deflection measurement.

From $C_{L_{\alpha}}$ and $C_{m_{\alpha}}$ static margin and neutral point are computed using the relation

$$
\begin{aligned}
& S M=\left(h,-h_{c}\right)=-C_{m_{\alpha}} / C_{L_{\alpha}} ; \\
& \therefore \quad h_{n}=h_{c}-C_{m_{\alpha}} / C_{L_{a}}
\end{aligned}
$$

The neutral point location obtained using the above equation is shown in figure 6 as a function of angle of attack. The neutral point data from reference 12 is also plotted for comparison. It is Seen that the comparison is good.

Figure 7 shows the model response to a large amplitude elevon step input. The effect of deflecting the elevon can be clearly seen in the beginning of the response where the Lif first decreases due to negative elevon deflection before building up with increase in angle of attack.

Figure 8 shows the variation of $C_{L}$ with angle of attack during an step elevon response. The trim $C_{L}$ is also shown in the figure. It can be seen that the dynamic Lift attainable is much more than the static Iift. The effect of increasing elevon magnitude on the Lift response is also shown in the figure. The labels 1 and 1.4 indicates the input amplitude with respect to the first input which is taken as one. While the responses are essentially same in the low angle of attack region, they differ at large angles of attack. This is attributed to flow separation, leading edge vortex breakdown, aerodynamic lags and hysteresis. These responses show the dynamic Lift effects and the Lift attainable during high angle of attack maneuvers beyond stall.

Figure 9 shows the variation of $C_{m}$ with angle of attack due to an elevon step input. It can be Seen from the figure that the pitching moment is zero at the beginning and at the end as the model moves from one trim condition to the other while the angle of attack changes from one trim to the other.

These large amplitude lift and pitching moment responses are useful in aerodynamic modelling at high angles of attack.

\section{Conclusions}

A novel method of generating comprehensive longitudinal aerodynamic data of aircraft configuration using dynamic wind tunnel simulation has been presented and demonstrated.

The aerodynamic data generated include

i. Trimmed Lift characteristics

ii. Location of neutral point and its variation with angle of attack

iii. Static and dynamic stability derivatives

iv. Dynamic İff and pitching moment response at high angle of attack.

The advantage of this method is the simplicity of model instrumentation and wind tunnel testing. It promises to be a cost effective experimental technique of generating comprehensive aerodynamic data for stability and control studies.

\section{Acknowledgements}

The contributions of $\mathrm{Mr}$. Basappa in wind tunnel testing and data processing; Mr B.K.KBhagwan in model fabrication; and Mr. S.R.Rajan in instrumentation are gratefully acknowledged.

\section{References}

1. Anon.: USAF Stability \& Control Datcom. Air Force Flight Dynamics Lab., Wright Patterson Air force Base, Aug. 1968.

\section{Orlik-Rückemann, K J.: Review of techniquesfor determination of dynamic stability parameters in wind tunnels. AGARD LS-1 14, $198 \mathrm{I}$.}

3. Bennett, R. M., et.al. Wind tunnel technique for determining stability derivatives from cable-mounted models. Journal of Aircraft, vol. 15, no. 5, May 1978, pp. 304 - 309.

4. Rohlf, D.: Control characteristics of DO 28 TNT model using dynamic simulation in wind tunnels. DFVLR IB 154.80/25. Dec. 1980. 
5, Wilhelm, K.; Gmelin, B.: Dynamic wind funnel testing for active control research. AGARDograph AG-262, Dec. 1984.

6. Heydari,F.: On the estimation of stability and control characferisfics of a generalised forward swept wing aircrafl. Ph.D. thesis, Aerodynamics dept., Cranfield Institute of Technology, UK. May 1986.

7. Balakrishna,S.; Niranjana,T:: Wind tunnel dynamic flying study of the pitching moment derivatives of SDM model in active control. AIAA Paper 87-2626, 1987.

8. Balakrishna,S.; Niranjana,T.; Rajamurthy, M.S.; Srinathkumar,S.; Rajan,S.R.; Singh,S.K:

Estimation of aerodynamic derivatives using Dynamic wind tunnel simulation technique. Proceedings of the NAL-DLR Symposium on System Identijcation. NAL SP 9324, Dec. 1993.(also DLR Mitt. 93-14, 1993).

9. Jarrah, M. A.: Low speed wind tunnel investigation of flow about Delta wings, oscillating in pitch to very high angle of attack. AIAA Paper 89-0295, 1989.
10. Hanff, E. S.; Kapoor, K.; Anstey, C. R. : Large amplitude High rate roll Oscillation system for the measurement of Non-linear loads. A I M Paper 90 1426, June 1990.

11. Torlund,P. -A: Wind tunnel force measurements and visualisation on a 60 deg. Delta wing in oscillation, steprise motion and gusts. Paper no. 10, AGARD conference on Manoeuvring Aerodynamics, AGARD CP 497, M a y 1991.

12. Vishwanath, P. R.; Patil, S. R; Aerodynamic characteristics of Delta Wing-body combinations at high angles of attack, paper 1959, The Aeronautical Journal, Vol. 28, May 1994.

13. Jategaonkar, R V. ; Plaetschke, E. : Maximum Likelihood parameter estimation from fight test data for general non-linear systems. DF VLR . FB 8314, 1983.

Table 1. Reference parameters of tbe model

\begin{tabular}{|ll|}
\hline & $0.289 \mathrm{~m}$ \\
Mean aerodynamicchord & $0.1084 \mathrm{~m}^{2}$ \\
Wing reference area & $0.03754 \mathrm{Kg} \cdot \mathrm{m}^{2}$ \\
\hline
\end{tabular}

Table 2 Estimated Longitudinal Derivatives

\begin{tabular}{|c|c|c|c|c|c|}
\hline $\begin{array}{c}\text { Trim angle of } \\
\text { attack } \\
\text { deg. }\end{array}$ & $\begin{array}{c}\text { Trim elevon } \\
\text { deg. }\end{array}$ & $\begin{array}{c}C_{L_{\alpha}} \\
\mathrm{rad}^{-1}\end{array}$ & $\begin{array}{c}C_{m_{\alpha}} \\
\mathrm{rad}^{-1}\end{array}$ & $\begin{array}{c}C_{m_{q}}+C_{m_{\dot{\alpha}}} \\
\mathrm{rad}^{-1}\end{array}$ & $\begin{array}{c}C_{m_{\delta_{e}}} \\
\mathrm{rad}^{-1}\end{array}$ \\
\hline 5.3 & 6.14 & 2.42 & -0.181 & -1.27 & -0.284 \\
\hline 6.7 & 5.54 & 2.31 & -0.142 & -1.52 & -0.317 \\
\hline 11.0 & 4.00 & 2.18 & -0.116 & -1.72 & -0.413 \\
\hline 14.6 & 3.10 & 2.25 & -0.141 & -1.89 & -0.410 \\
\hline 18.4 & 1.96 & 1.91 & -0.171 & -1.82 & -0.351 \\
\hline
\end{tabular}




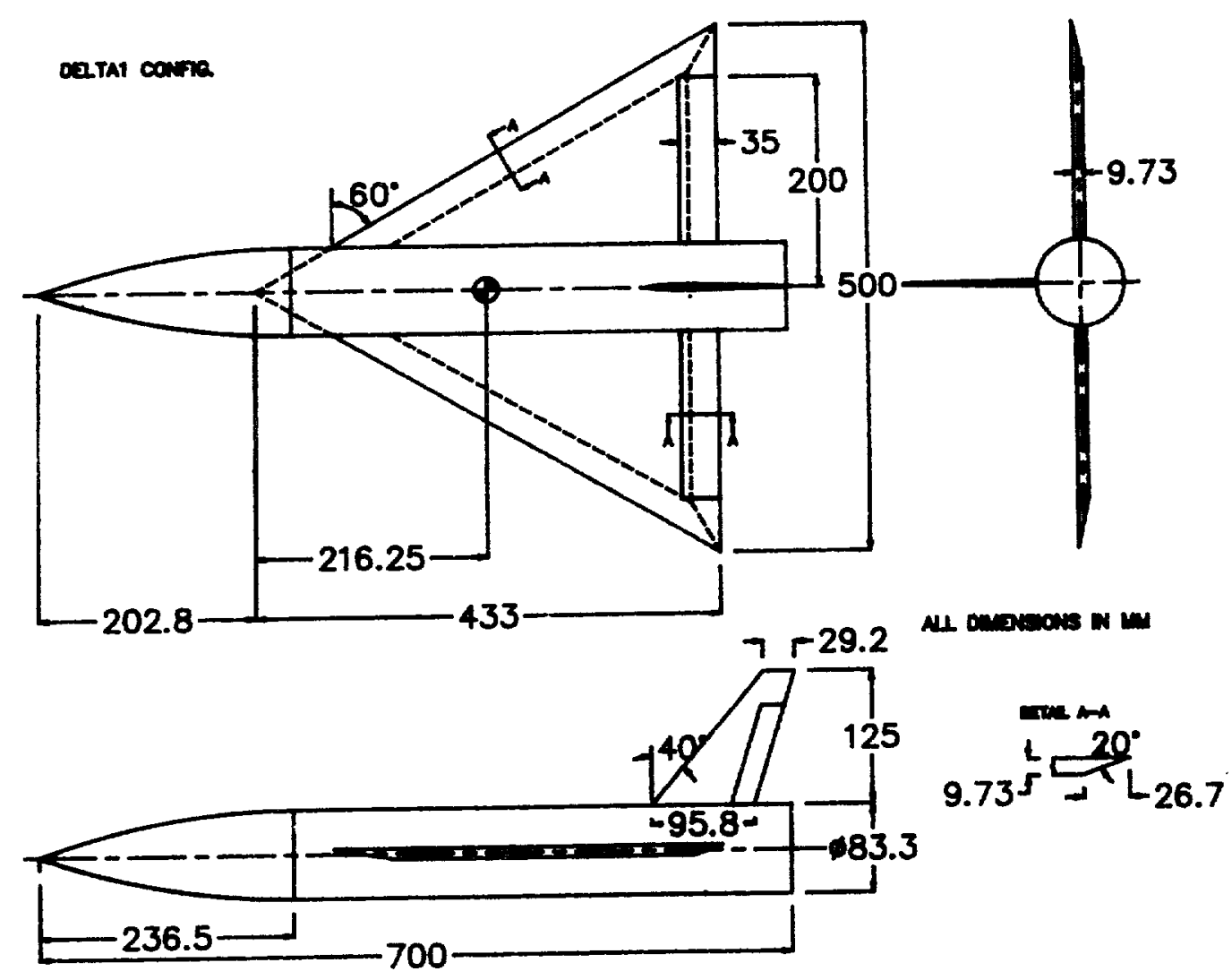

Figure 1. Geometric details of the model

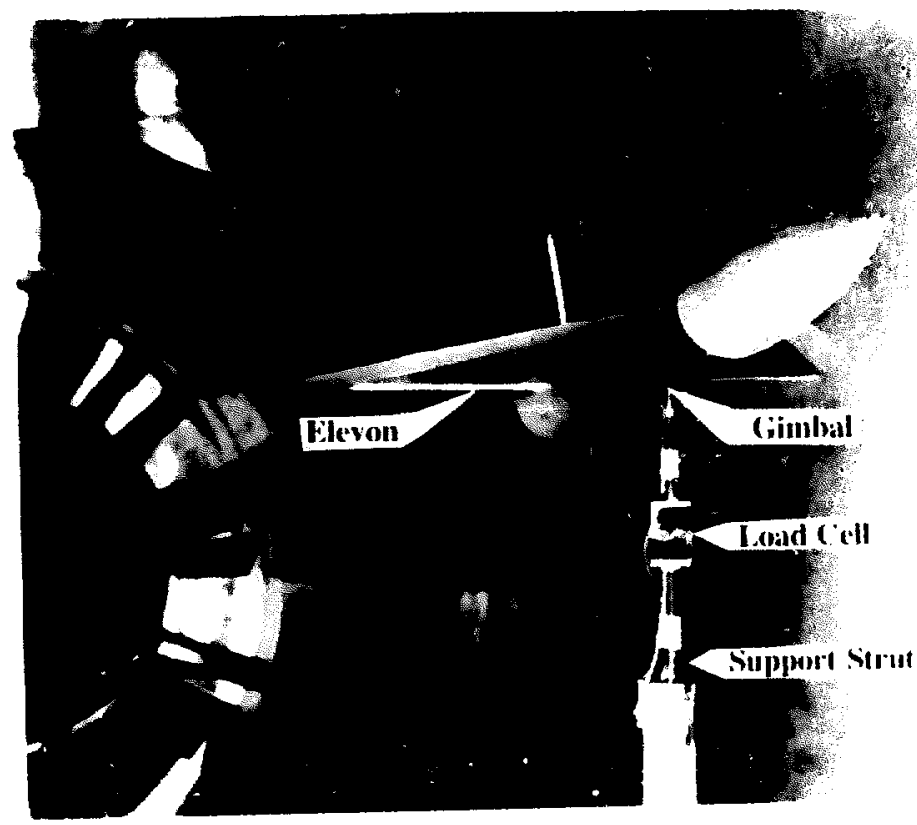

Figure 2. Delta wing model in the wind tunnel 


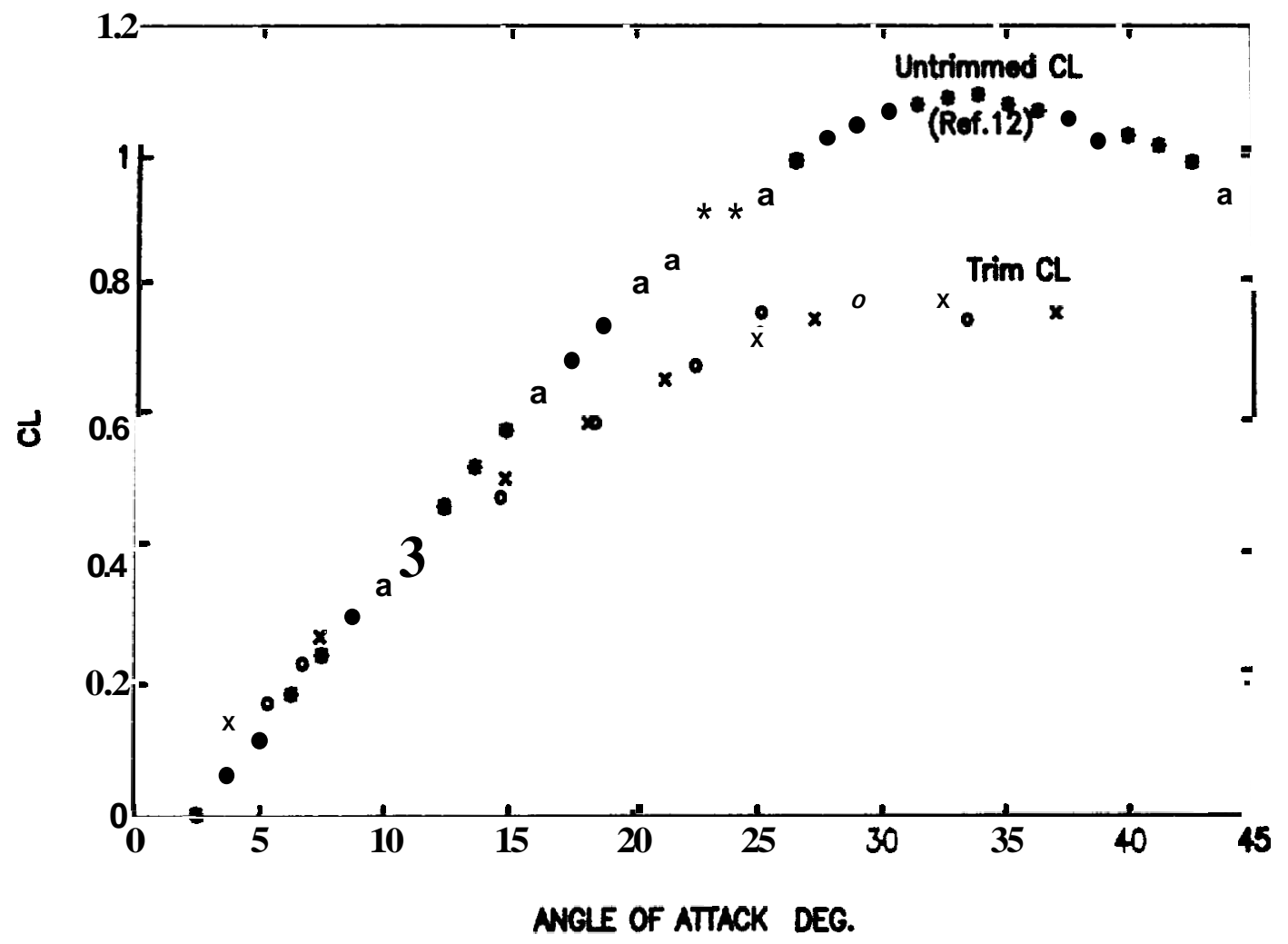

Figure 3. Trimmed Lift characteristics
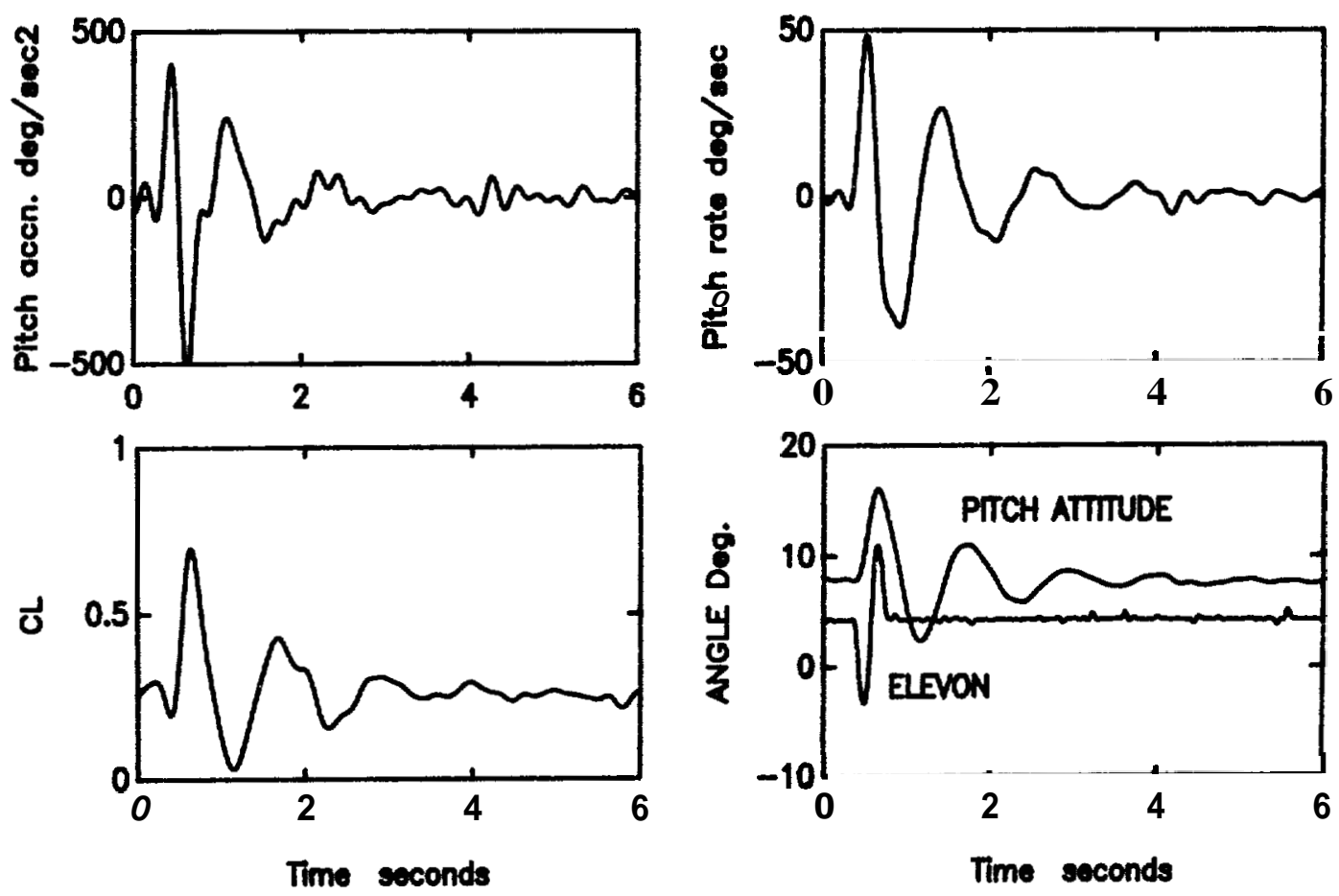

Figure 4. Response of aircraft model to an elevon doublet 


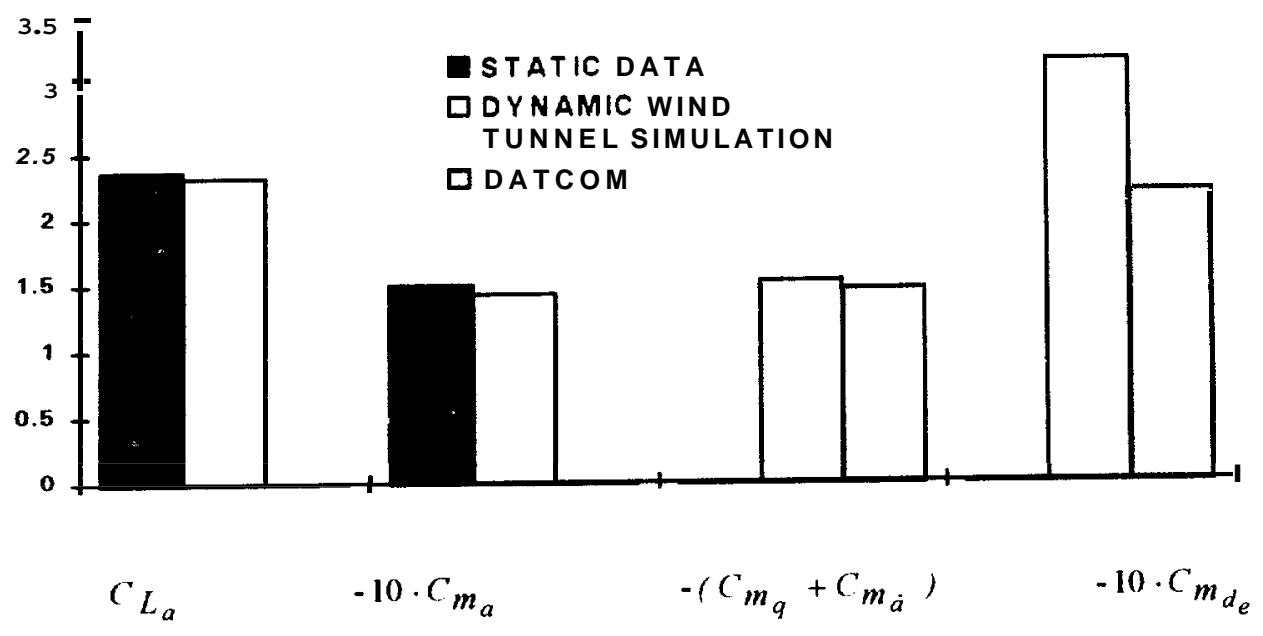

Figure 5. Comparison of estimated derivatives with static test data and Datcom estimates

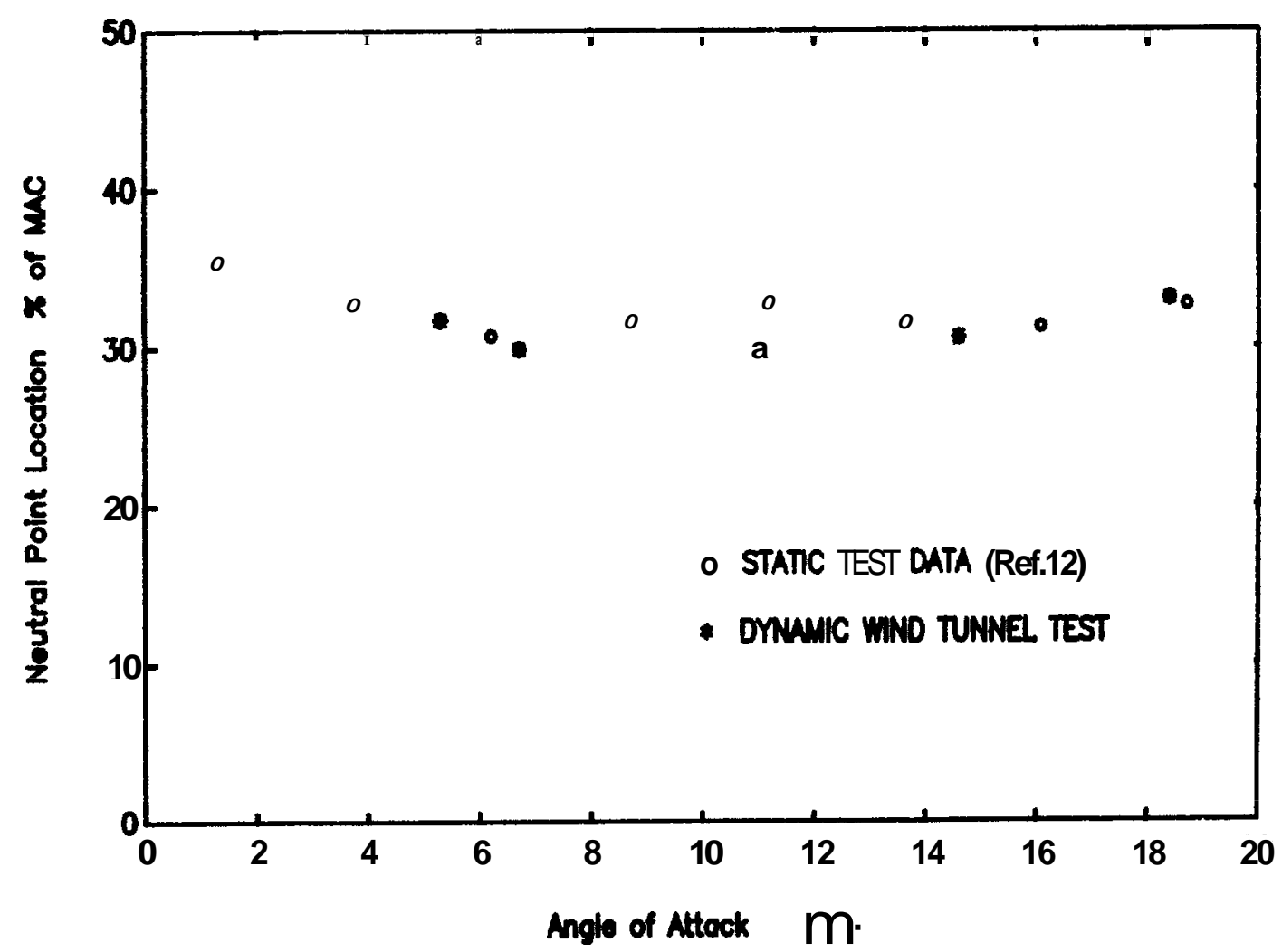

Figure 6. Variation of neutral point with angle of attack 

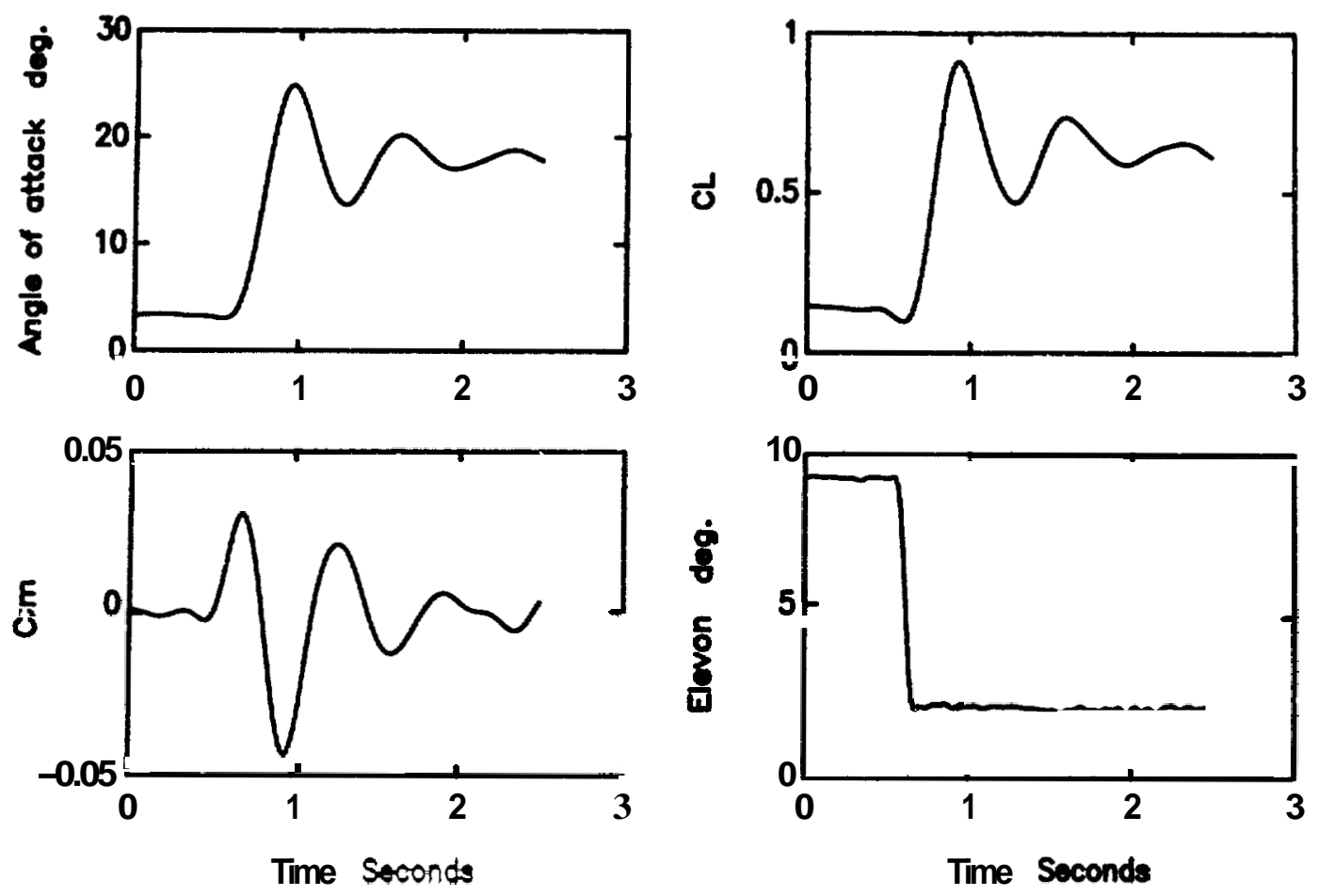

Figure 7. Large amplitude response of the model to a step Elevon input

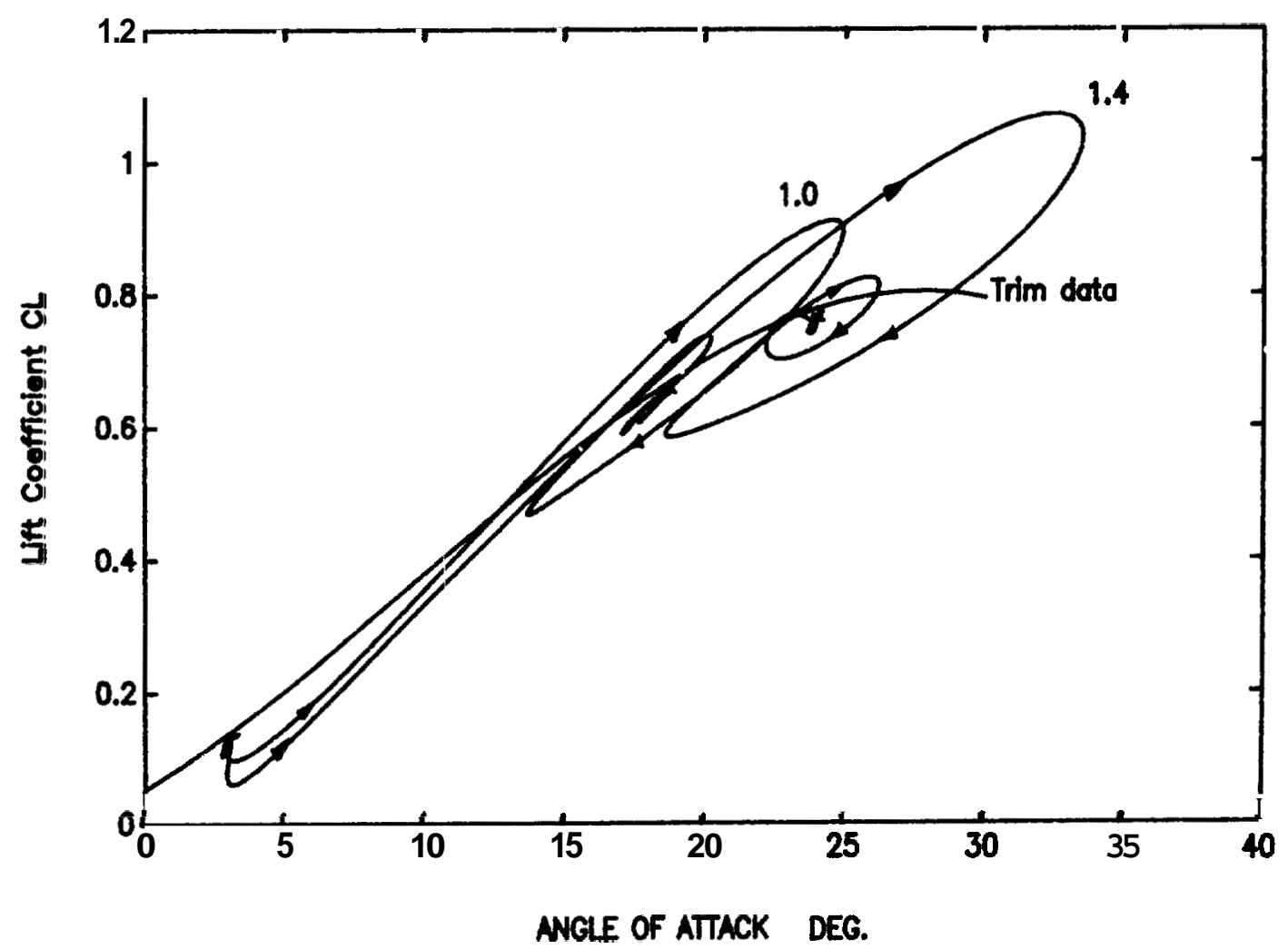

Figure 8. Large amplitude Lift responses 


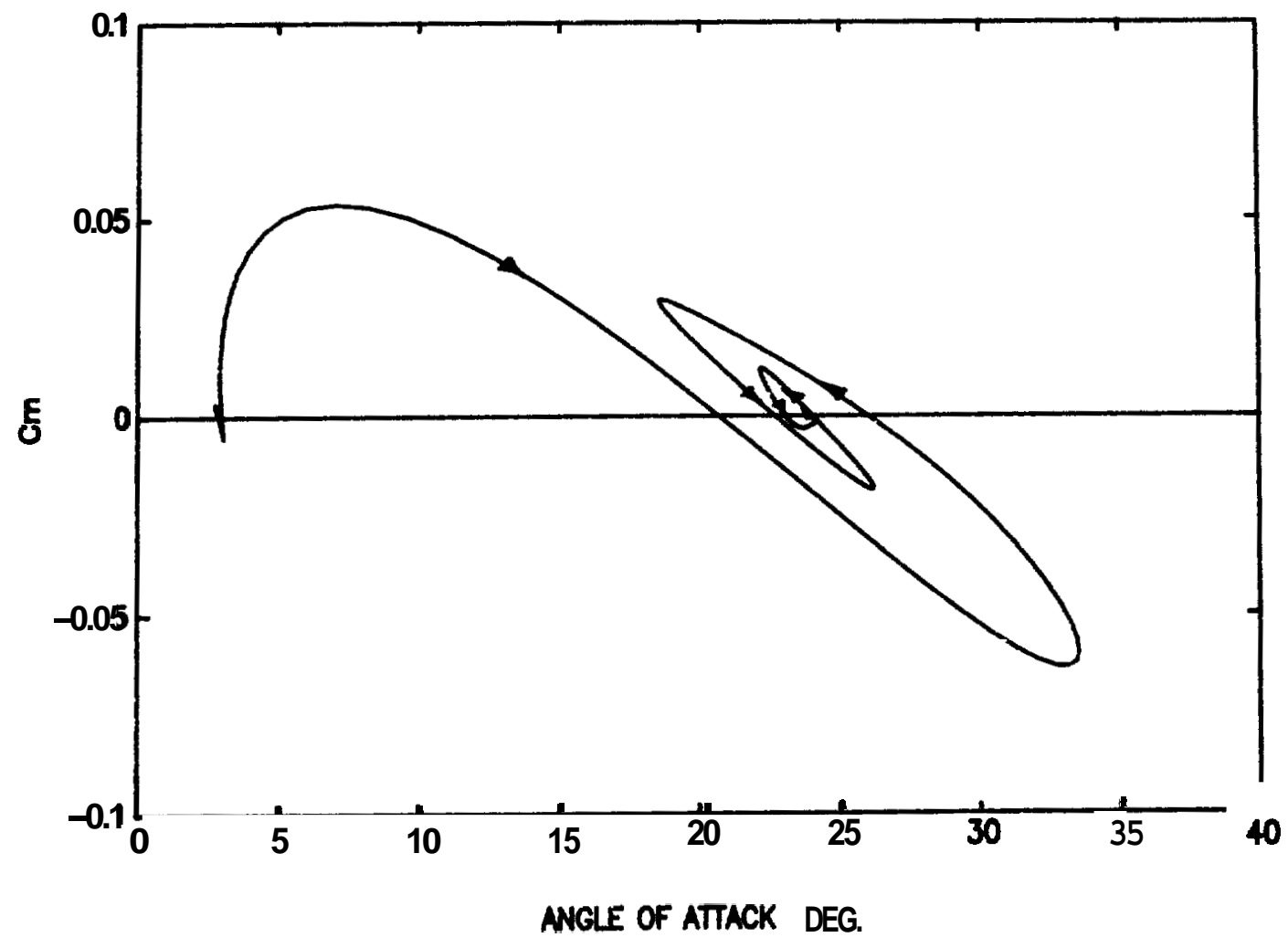

Figure 9. Large Amplitude pitching moment response 


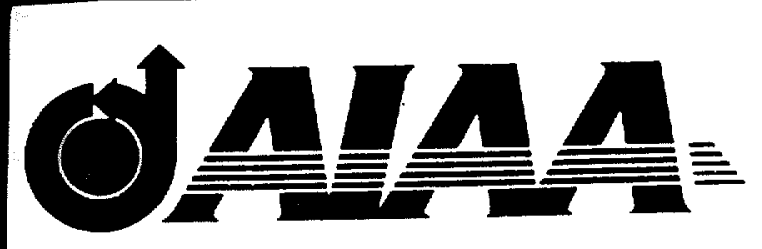

\title{
AIAA 96-0777 \\ Generation of Comprehensive Longitudinal Aerodynamic data using Dynamic wind tunnel simulation
}

\author{
M.S.Rajamurthy \\ National Aerospace Laboratories \\ Bangalore, INDIA
}

\section{4th Aerospace Sciences Meeting \& Exhibit January 15-18, 1996/ Reno, NV}

